\title{
Relation between natural cleansing effect and angularity of coastal gravel
}

\author{
S. Hamada ${ }^{1}$, N. Sawano ${ }^{2} \&$ R. Aps ${ }^{3}$ \\ ${ }^{1}$ Geological Survey of Hokkaido, Department of Marine Geosciences, \\ Otaru City, Japan \\ ${ }^{2}$ Inaoki Educational Institute \& Seiryo Women's Junior College, \\ Kanazawa City, Japan \\ ${ }^{3}$ University of Tartu, Estonian Marine Institute, Tallinn, Estonia
}

\begin{abstract}
Serious environmental contamination will arise once spilled oil hits the coastal area. A gravel beach is commonly hard for oil recovery because these areas are hard to approach in order to conduct cleanup work. Also, stranded oil will easily be penetrated into the coastal sediment of gravel. In this study, energy of wave exposure was analyzed using the method of image analysis to gravel shapes. As a result, the shape of gravel on a beach is affected by the energy of wave and then provides natural cleansing ability. These effects were examined by an actual oil spill by "Nakhodka" which happened in 1997. In the field survey, projected images of cobble-sized andesitic gravel were taken by a digital camera. Then shapes of them were analyzed by the software "ImageJ" and a common spreadsheet. All the images were changed to 720-angled polygon then "bending angles" were measured to decide "Angularity Indexes" of gravel. Oil residual time of monitoring points of Nakhodka and the indexes were examined and then a strong correlation coefficient $\left(\mathrm{R}^{2}=0.858\right)$ has been observed. Also, the natural cleansing ability for oil can be estimated by image analyses of coastal gravel.
\end{abstract}

Keywords: oil spill, gravel beach, ESI mapping, risk assessment.

\section{Introduction}

In the continental shelf of the Island of Sakhalin, a consortium led by Royal Dutch Shell is operating the Sakhalin II oil and gas project that is the largest 
foreign investment of Russia [1]. Considering the risk associated with oil spills, contingency plans will have to be established for Soya strait.

In January 1997, the Russian tanker Nakhodka spilled more than 8,000 tons of heavy-C oil. The northern part of the Noto Peninsula (Figure 1) was heavily damaged. Shoreline cleanup and recovery works were hard and cost much for oil events. Recovery works were difficult in gravel beaches because access for traffic to the oiled sites is dangerous and stranded oil is penetrated easily into the sediment [2]. Based on the lessons of Nakhodka, the natural cleansing ability depending on the feature of gravel will have to be evaluated then be reflected in contingency planning.

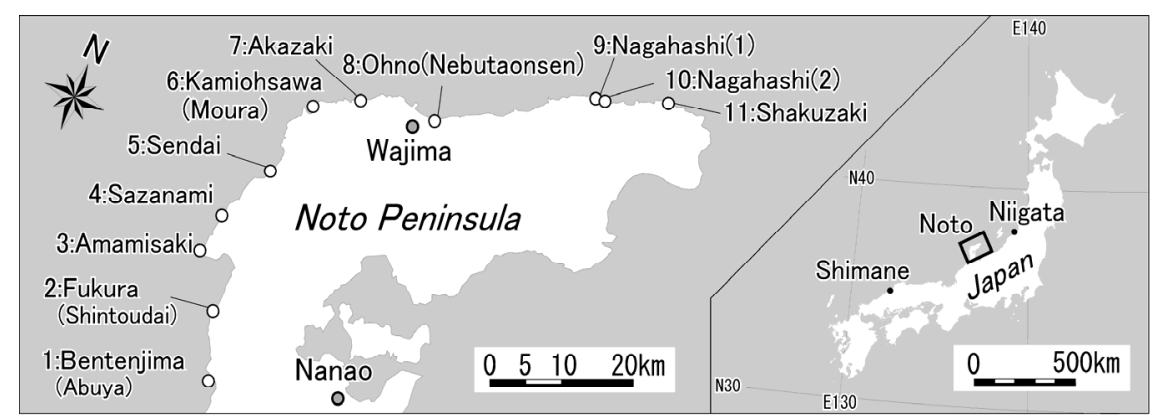

Figure 1: Location of field survey area.

Sawano [2] reported a relation between oil residue and the type of coast (sandy, rocky, etc) by his on site monitoring of Nakhodka. Also, Hamada [3] made a report on the oil impacted beach of Nakhodka from the point of beach topography and sediments and showed the relation between gravel shape and oil residue of the gravel beaches.

The relation between "angularity" of coastal gravel and oil residue was discussed, based on the case study of Exxon Valdez by Hayes [4]. His evaluation of angularity, however, was basically based on human impression using the "roundness chart" proposed by Powers [5]. Visual inspection is a convenient way for field research, but an inevitable difference occurs even between well trained personnel. Our study presents the relation between image-analyzed angularity and length of oil residue after a big scale oil spill. In this paper, a quantitative approach will be made to evaluate the angularity of coastal gravel.

\section{Evaluation strategies for gravel angularity}

It is known that "roundness of particle" was defined by Wadell [6]. Generally, evaluation of gravel roundness has been measured by visual impression using the "roundness chart" proposed by Powers [5] or "Krumbein's roundness chart" [7]. 
Then another approach was used to evaluate angularity using image analyses without eye bias.

Some of the oiled shorelines of this study are hard to access even by specially equipped automobiles, and then correctly weighted equipment was selected for logistic purposes. A common digital camera and a portable stand (Figure 2) were used in the study sites. Images of coastal gravel are taken using the equipment. After a field survey, a public domain software "ImageJ" and spreadsheet were used to calculate the value of gravel angularity.

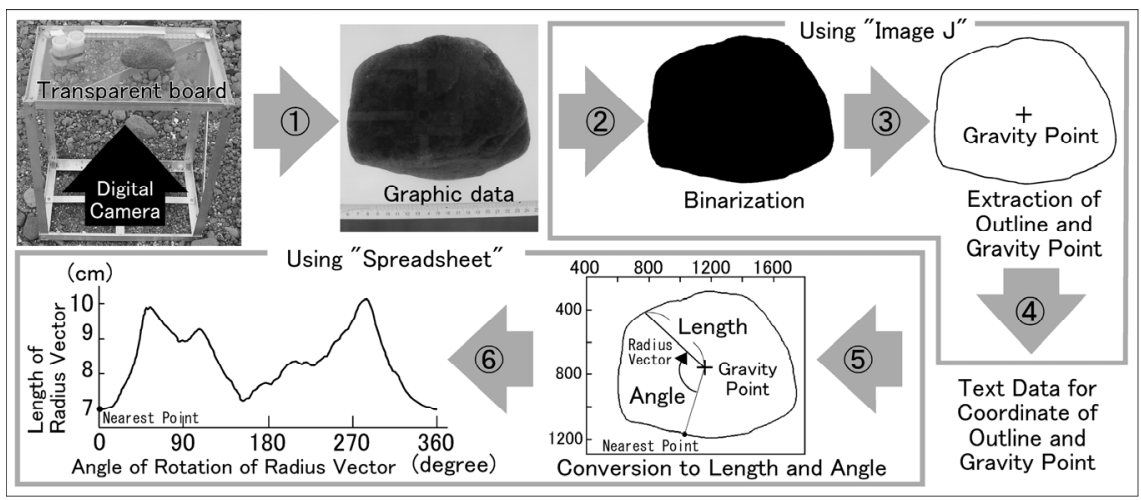

Figure 2: $\quad$ Photographing of gravel image and extraction of outline data.

\subsection{Imaging method and profile extraction}

\subsubsection{Gravel sampling}

Gravel samples for this study were andesitic large-cobble-sized (the diameter was from 12.8 to $25.6 \mathrm{~cm}$ ). Fifty cobbles were taken from the beach where oil remained. In some study sites where the oil was removed completely, samples were collected from the part of the berm located in the upper tidal zone of the gravel beach.

\subsubsection{Images of gravel shape taken by digital camera}

The maximum projected plain of gravel was used as the shape of gravel. Gravel was put on the transparent board, and taken by the camera fixed under the board (Figure 2). Shadows did not appear around the gravel and clear-cut of projected shapes can be taken on this process. With our equipment, 1 pixel of the image is equivalent to $0.15 \mathrm{~mm}$ of actual length.

\subsubsection{Binarization and extracting profile}

The photo images of the gravel were binarized into black (for gravel) and white (for background) by ImageJ (Figure 2) and the circumference of shape was extracted from the image (Figure 2). Subsequently, the coordinate of the center of gravity and the length from the center of gravity to circumference (length of radius vector) were calculated (Figure 2). Based on the length and the angle of radius vector, the gravel shape was expanded to a bent line on the graph 
(Figure 2). If the sample is rounded, the bent line becomes smooth, because the length between the centre of gravity and the peaks are always stable. On the other hand, if the sample was angular, the graph becomes irregular and wavy in accordance with the surface roughness of the sample.

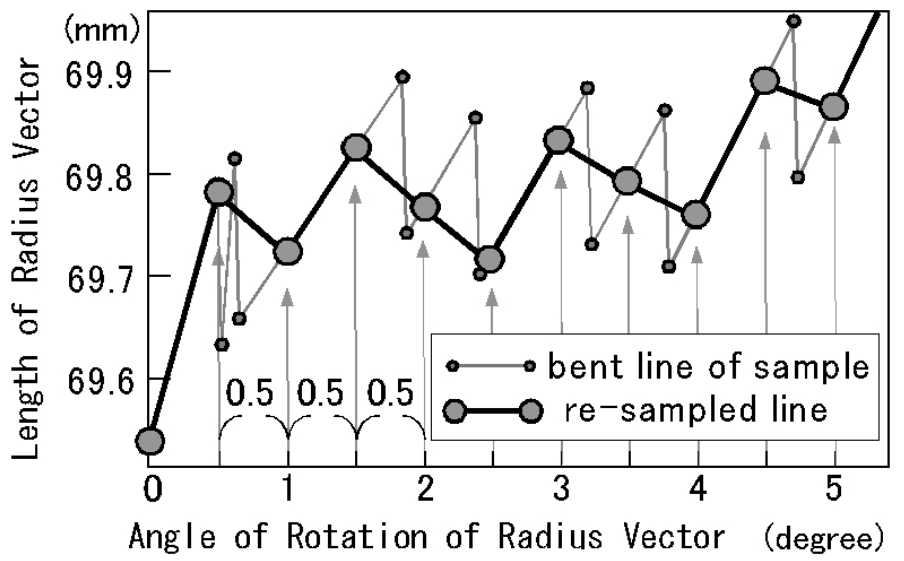

Figure 3: Re-sampling of bent line at intervals of 0.5 degrees.

\subsubsection{Re-sampling}

The bent line acquired from the photo image of gravel has many bending points and interval of those are irregular (Figure 3). For the purpose of measuring the angularity of the line, new lines were sampled again. The bending points of the new lines were measured every 0.5 degrees of angle rotation of radius vector (Figure 3). In these processes, each bent line has transformed to a 720-angled polyline.

\subsection{Angularity index based on bending angle}

In order to determine the best index for the evaluation of gravel angularity, we have developed 5 kinds of index [8] and compared them. As a result, we conclude that the angularity index based on the bending angle is the best.

The index was calculated from the bending angle at each 720 bending point of the 720-angled polyline (Figure 4). For example, the bending angle at Pn in Figure 4 is defined as an angle between the linear line from Pn-1 to Pn and the line from $\mathrm{Pn}$ to $\mathrm{Pn}+1$. The horizontal distance from $\mathrm{Pn}-1$ to $\mathrm{Pn}$ or $\mathrm{Pn}$ to $\mathrm{Pn}+1$ has 5 degrees. At every 720 points, the bending angles are measured in the same way. If the angle is convex, the value of bending angle becomes plus. On the other way, concave angle shows minus. If the gravel shape is complete round, every bending angle becomes 0 degrees.

The 95 percentile value of all bending angles at the 720 points was used as the angularity index. The more "angular" the gravel is, the "larger" the index becomes. 


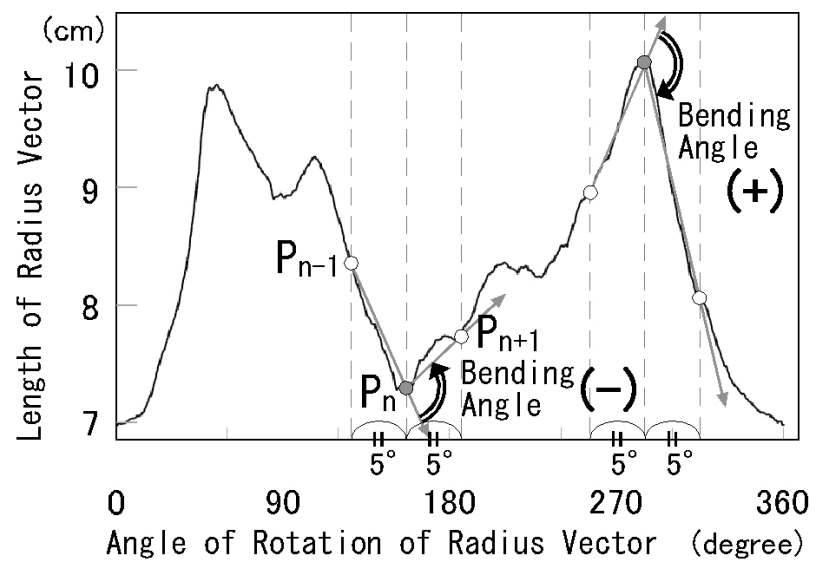

Figure 4: The bending angle at each bending point of the line.

\section{Gravel angularity and oil residual time in Nakhodka oil spill}

More than 8000 tons of heavy crude oil was discharged from the wreck of the tanker Nakhodka on January 2nd 1997. More than $1300 \mathrm{~km}$ of shoreline was contaminated. The oiled shoreline along the Japan Sea was extended from Shimane to Niigata prefecture. Especially heavily contaminated sites in Noto Peninsula of Ishikawa prefecture were rich in gravel beach and cliff, then the oiled shoreline was hard to access, and the recovery works on it were seriously difficult. Subsequently, a considerable amount of stranded oil has been untouched on the beaches after the oil spill. The above mentioned quantitative estimations of angularities are applied to check the relation between the oil residual period and the index of gravel angularity (Figure 1). The survey points are located from Bentenjima to Shakuzaki on the Noto peninsula.

\subsection{Oil residual time}

Oil residual time at 74 beaches on the Noto Peninsula after the Nakhodka oil spill have been monitored by Sawano [2]. His study showed the degree of oil residue as "Heavy", "Light" or "None", and made it clear how it had changed at each survey point. Oil residual time in this paper uses his results, and defined as the time from "Heavy" to "Light" or "Light" to "None".

\subsection{Comparison between the angularity and oil residual time}

An angularity index was compared with the oil residual time at each survey point (Table 1, Figure 5). The shape of coastal gravel at No.4 Sazanami, No.5 Sendai, and No.8 Ohno are relatively rounded, and the stranded oil has remained for 2 to 4 years. On the other hand, at No.7 Akazaki, No.9 and 10 Nagahashi (1) (2), No.11 Shakuzaki, the shapes are relatively angular, and the oil has remained up to 8 to 9 years or more. As a result of the comparison, a high correlation 
coefficient was obtained between the angularity index defined by this study and oil residual time (table 1). The index defined by this study shows the more angular in shape the gravel is, the longer the oil stays. And the index obtained from the bending angle of convex has the highest correlation coefficient $\left(\mathrm{R}^{2}=\right.$ 0.858 ) with the oil residual time. Figure 5 shows the regression. The actual oil residual time on the gravel beach is observed within 1.5 years from the regression line. The equation of the regression line is as follows:

Residual time at gravel beach in Nakhodka oil spill (year)

$$
=(\text { Index }-3.41) / 2.89
$$

Table 1: Correlation coefficient between the angularity index of coastal gravel and residual time of stranded oil at each survey point. The index of each survey point is the average of 50 pieces of gravel.

\begin{tabular}{|rl|c|c|}
\hline No. & Survey point & $\begin{array}{c}\text { Residence time of oil } \\
\text { (years) }\end{array}$ & $\begin{array}{c}\text { Angulality index of } \\
\text { coastal gravel (deg.) }\end{array}$ \\
\hline 1 & Bentenjima (Abuya) & $>8.6 * 2$ & 30.5 \\
2 & Fukura (Shintoudai) & 6 & 20.7 \\
3 & Amamisaki & 5 & 20.6 \\
4 & Sazanami & 2 & 11.7 \\
5 & Sendai & 4 & 11.1 \\
6 & Kamiohsawa & 5 & 19.8 \\
7 & Akazaki & 8.9 & 27.9 \\
8 & Ohno (Nebutaonsen) & 4 & 11.4 \\
9 & Nagahashi 1 (Ohtani) & $>8.9$ & 33.1 \\
10 & Nagahashi 2 (Gas Station) & $>8.9$ & 24.4 \\
11 & Shakuzaki & $>8.9$ & 29.3 \\
\hline Correlation coefficient between shape index of gravel $\left(\mathrm{R}^{2}\right)$ & 0.858 \\
and residence time of oil after Nakhodka oil spill & \multicolumn{2}{c}{} \\
\hline
\end{tabular}

*1: after Sawano,2007*2: Oil residue was find at field survey in July 2005

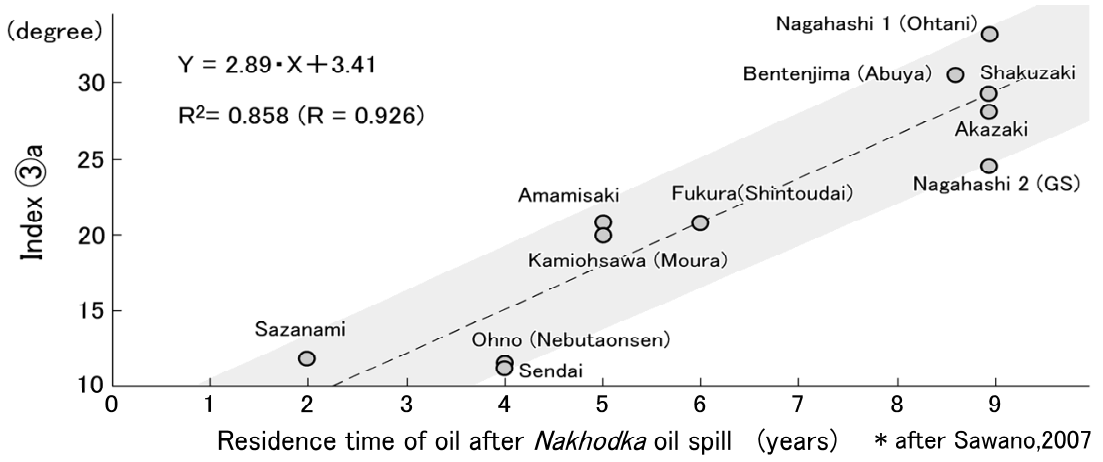

Figure 5: Relation between oil residual time at each survey point and gravel angularity index. 


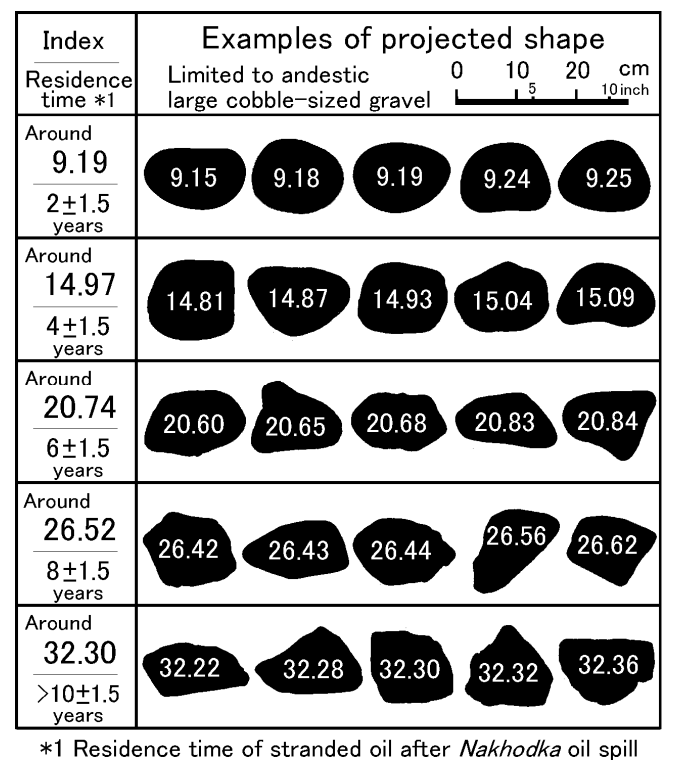

Figure 6: $\quad$ Examples of projected shapes of gravel angularity index.

Figure 6 shows the examples of the shape of Index (around 9.19, 14.97, 20.74, 26.52 and 32.30). In total, each classification of the shape is equivalent to the oil residual time of 2, 4, 6, 8 and 10 years after the Nakhodka incident.

\subsection{Relation between angularity of gravel and natural cleansing effect}

Natural cleansing effects on a gravel beach are thought to be providing a wave washing effect. Based on the field observations, wave strength at the beach is different from coastal topography. For example, on a sheltered gravel beach where wave energy was decreased by wave cut bench, the waves could not run up to the beach (Figure 7 lower). On the other hand, on the exposed gravel beach where strong waves directly hit, the gravel is rolling up and down (Figure 7 upper).

The highest Backshore Height ("BH" in Figure 7) shows the maximum elevation of waves run up in the shoreline. It was observed as a vegetation limit or storm berm in the beach. These are showing "maximum wave strength" on a beach. In this study, we have measured and compared the elevation of highest Backshore Height $(\mathrm{BH})$ with the angularity index of coastal gravel.

As a result, the angularity index of gravel highly correlated with the highest $\mathrm{BH}$ of the gravel beach $\left(\mathrm{R}^{2}=0.79\right)$ (Figure 8$)$. On a sheltered beach, the elevation of $\mathrm{BH}$ becomes lower in association with the shape of gravel as it becomes angular. On the other hand, on an exposed gravel beach, the level of $\mathrm{BH}$ becomes higher and the shape of gravel becomes rounded. 

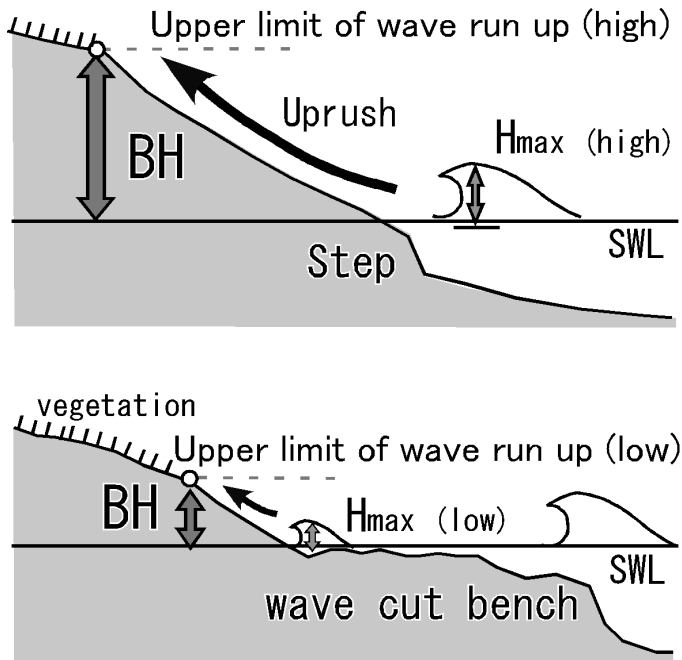

Figure 7: Relation between wave strength at beach and upper limit of wave run up height.

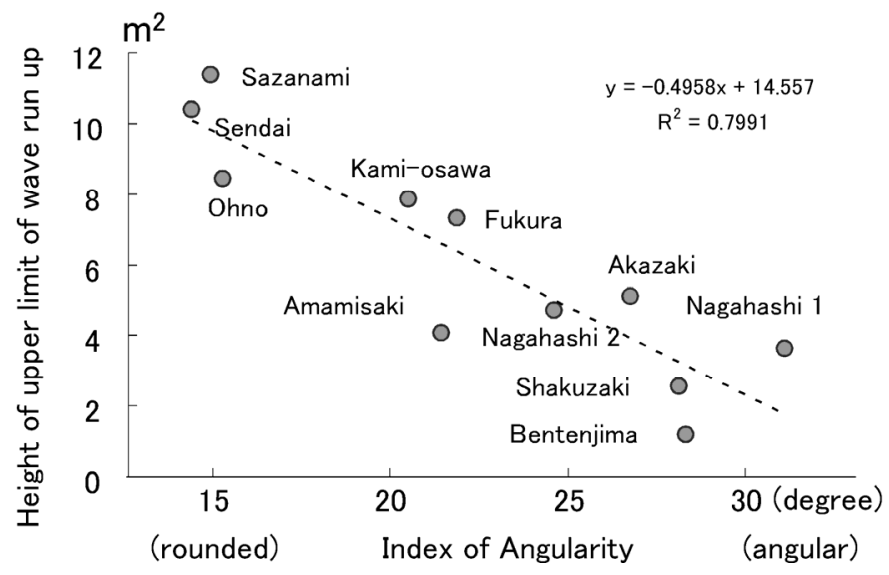

Figure 8: Relation between the index of angularity and height of upper limit of wave run up.

\section{Conclusion}

In this study, we have tried a quantitative evaluation of gravel angularity then compared oil remaining time. As a result, the angularity index of the gravel has high correlation with the oil residual time on a gravel beach $\left(\mathrm{R}^{2}=0.878\right)$. And we 
propose to examine the "convex of the shape" to evaluate the natural cleansing effect on a gravel beach.

The angularity index of gravel shape has a high correlation with the $\mathrm{BH}$ of a gravel beach. It means that the wave energy has a great influence on gravel shape.

It is concluded that the angularity of the gravel shows the natural washing effect on a gravel beach, and quantitative angularity will be used for the index of natural persistence of oil. As of the moment, it is difficult to make a "correct" prediction of the rate of oil removal from the oiled gravel beaches because so many conditions may affect it. However, a "relative" comparison of the selfcleansing effect on the gravel beach, for example, which part of shoreline should be cleaned faster, will be predicted. This result should be reflected for developing a shoreline information map for oil spill counter measures.

\section{References}

[1] Murakami, T., Oil and natural gas developing projects in the Sakhalin continental shelf, Sakhalin Offshore Oil and Gas Development and Environmental Protection, ed. T. Murakami, Hokkaido University Press: Sapporo, pp.250, 2003.

[2] Sawano, N. Analysis of Oil Residue based on Long-term Shoreline Monitoring after Nakhodka Oil Spill, Papers on Environmental Information Science, 20, pp. 303-308, 2007.

[3] Hamada, S. Remaining position of stranded oil in beach profiles. Report of the Geological Survey of Hokkaido, 72, pp. 73-84 (In Japanese), 2001.

[4] Hayes, M. O. An Exposure Index for Oiled Shorelines, Spill Science \& Technology Bulletin, 3(3), pp. 139-147, 1996.

[5] Powers, M. C. A new roundness scale for sedimentary particles, Journal of Sedimentary Petrology, 23, pp. 117-119, 1953.

[6] Wadell, H. Sphericity and roundness of rock particles, Journal of Geology, 41, pp. 310-331, 1933.

[7] Krumbein, W. C. Measurement and geologic significance of shape and roundness of sedimentary particles, Journal of Sedimentary Petrology, 11, pp. 64-72, 1941.

[8] Hamada, S. Relation between oil residues and angularity of coastal gravel. Proceedings of PACON 2007, pp. 108-115, 2007. 